\title{
Interação entre Nematicidas e Herbicidas Aplicados no Plantio DA CANA-DE-AÇÚCAR ${ }^{1}$
}

\author{
Interaction Between Nematicides and Herbicides Applied on Sugarcane Plantations
}

DINARDO-MIRANDA, L.L. ${ }^{2}$, GIL, M.A. ${ }^{2}$ e GONÇALVES, R.F. ${ }^{3}$

\begin{abstract}
RESUMO - O efeito do sinergismo entre os nematicidas aldicarb, carbofuran e terbufós, aplicados no sulco de plantio, e os herbicidas clomazone, metribuzin e tebuthiuron, aplicados em pré-emergência, oito dias após o plantio da cana-de-açúcar foi avaliado em experimento conduzido em solo arenoso. Os sintomas mais acentuados de fitointoxicação foram observados nas parcelas que receberam metribuzin + terbufós ou tebuthiuron + terbufós. Metribuzin e tebuthiuron foram os herbicidas que provocaram sintomas mais acentuados de fitointoxicação, e o tebuthiuron prejudicou o desenvolvimento inicial da cultura, representado pelo número de perfilhos por metro. Apesar disso, não se observou redução significativa de produtividade em função da aplicação conjunta de nematicidas e herbicidas. Na média, aldicarb e carbofuran incrementaram a produtividade de colmos em $12 \mathrm{t} \mathrm{ha}^{-1}$. Parcelas tratadas com clomazone produziram, em média, significativamente mais que as tratadas com metribuzin.
\end{abstract}

Palavras-chave: fitointoxicação, Saccharum.

\begin{abstract}
The interaction between the nematicides aldicarb, carbofuran and terbufos and the herbicides clomazone, metribuzin and tebuthiuron, applied on sugarcane plantations, was evaluated in an experiment conducted in sandy soil. Plots treated with metribuzin + terbufos or tebuthiuron + terbufos presented the most severe phytotoxicity symptoms. The herbicides metribuzin and tebuthiuron caused high phytotoxicity and tebuthiuron reduced the number of stalks in the plots, five months after planting. In spite of this, yield reduction due to nematicide and herbicide application was not observed. Aldicarb and carbofuran increased sugarcane yield at 12 ton $\mathrm{ha}^{-1}$. Plots treated with clomazone produced significantly more than plots treated with metribuzin.
\end{abstract}

Keywords: phytotoxicity, Saccharum.

\section{INTRODUÇÃO}

Os danos causados por nematóides à canade-açúcar podem ser mensurados com clareza em áreas experimentais infestadas, nas quais se faz aplicação de nematicidas por ocasião do plantio, tal como observado em DinardoMiranda et al. (1998; 2003), que constataram aumentos de produtividade de 25 a $30 \%$ no primeiro corte da cultura, decorrentes do controle químico de nematóides. Incrementos significativos de produtividade agrícola, aliados à falta de variedades comerciais resistentes a nematóides e à ineficiência ou dificuldade de aplicação de medidas físicas, biológicas ou culturais de controle desses parasitos, têm contribuído para o emprego crescente de nematicidas na implantação do canavial.

Assim como os nematóides, as plantas daninhas também podem causar reduções de produtividade, seja pela competição com a

Recebido para publicação em 9.8.2005 e na forma revisada em 4.8.2006.

2 Eng.-Agr., Pesquisadora, Centro de Cana-de-Açúcar, Instituto Agronômico/APTA, Caixa Postal 206, 14001-970 Ribeirão Preto-SP, <leiladinardo@iac.sp.gov.br>. ${ }^{3}$ Eng.-Agr., Usina Iracema, Caixa Postal 31, 13495-000 Iracemápolis-SP. 
cultura por água, nutrientes e radiação solar, seja por efeitos alelopáticos (Pitelli, 1985). Como o controle de plantas daninhas, em canade-açúcar, é feito quase que exclusivamente com herbicidas, muitas áreas recebem nematicidas ou inseticidas no sulco de plantio e herbicidas, em cobertura, logo a seguir, o que, em certas condições, resulta em aumento dos sintomas de fitointoxicação do herbicida (Dinardo-Miranda, 2001a, b).

No Brasil, os primeiros registros de ocorrência de fitointoxicação causada por herbicidas em áreas tratadas com nematicida foram feitos na década de 1980, com a descrição de severas injúrias nas folhas de canaviais tratados com carbofuran no sulco de plantio e tebuthiuron, em pré-emergência das plantas daninhas, logo após plantio (Blanco et al., 1980; Copersucar, 1982). Mais recentemente, Dinardo-Miranda et al. (2001b) verificaram que a aplicação dos herbicidas metribuzin ou da mistura de clomazone + (diuron + hexazinona), em área cultivada com a variedade RB845257, resultou em redução de produtividade nas parcelas tratadas com carbofuran ou terbufós, o mesmo não ocorrendo quando se utilizou tebuthiuron. Posteriormente, trabalhando com a variedade RB72454, cultivada em sistema de cana de ano, Dinardo-Miranda et al. (2001a) observaram redução de produtividade em parcelas tratadas com tebuthiuron e terbufós, mas não naquelas tratadas com tebuthiuron e carbofuran ou aldicarb. Em 2004, Negrisolli et al., trabalhando com a variedade RB855113, verificaram que os nematicidas carbofuran e terbufós não interferiram na intoxicação causada por herbicidas, entre os quais metribuzin, tebuthiuron e clomazone.

Essas referências ilustram quão complexa é a associação entre nematicidas e herbicidas em cana-de-açúcar. Na tentativa de melhor entender o processo, o presente trabalho foi conduzido.

\section{MATERIAL E MÉTODOS}

Conduziu-se um experimento em área de solo arenoso (Argissolo amarelo), no município de Itirapina-SP, em fazenda pertencente à Usina Iracema, cultivada com a variedade SP87-365, cujo plantio foi realizado em 7.3.2002. Para isso, utilizou-se o delineamento de blocos ao acaso, com parcelas subdivididas e quatro repetições. Cada parcela foi representada por seis sulcos de $40 \mathrm{~m}$ de comprimento, com 1,5 m de espaçamento entre sulcos, dividida, ao longo do comprimento, em quatro subparcelas de seis sulcos de $8 \mathrm{~m}$, separadas entre si por um carreador de $2 \mathrm{~m}$. Às subparcelas correspondeu a aplicação dos tratamentos nematicidas, a saber: testemunha; aldicarb 1.800 g i.a. ha ${ }^{-1}$, carbofuran 2.275 g i.a. ha-1 e terbufós $2.550 \mathrm{~g}$ i.a. ha- ${ }^{-1}$. Os nematicidas foram aplicados sobre os toletes, no sulco de plantio, imediatamente antes da cobertura dos sulcos. Os tratamentos herbicidas avaliados, testemunha (sem herbicida, com capina manual), clomazone 1.000 g i.a. ha-1, tebuthiuron $1.000 \mathrm{~g}$ i.a. ha ${ }^{-1}$ e metribuzin 1.680 g i.a. ha-1, foram aplicados em cobertura, com equipamento tratorizado, em 15.3.2002, oito dias após plantio.

As avaliações de fitointoxicação foram realizadas em 5.4.2002, 19.4.2002, 3.5.2002, 16.5.2002, 3.6.2002 e 28.6.2002, ou seja, $21,35,49,62,79$ e 104 dias após a aplicação dos herbicidas, respectivamente. Em cada avaliação, atribuíram-se notas às plantas das parcelas de acordo com a escala da EWRC (1964). Cinco meses após o plantio (6.8.2002) fez-se uma avaliação do estande da cultura, contando-se os perfilhos nos quatro sulcos centrais de cada parcela. Aos 5, 8 e 10 meses após plantio (6.8.2002, 14.10.2002 e 6.12.2002), foram feitos levantamentos nematológicos. Para isso, no primeiro sulco de cada parcela, coletou-se uma amostra de cerca de $50 \mathrm{~g}$ de raízes de cana-de-açúcar. Em laboratório, os nematóides presentes nas amostras foram extraídos pela combinação dos métodos de peneiramento com flotação em centrífuga em solução de sacarose, de acordo com Coolen \& D’Herde (1972) e Jenkins (1964). Por ocasião da colheita, em 8.9.2003, foram obtidas as produtividades agrícolas, pesando-se os colmos dos quatro sulcos centrais de cada parcela.

A área experimental foi mantida no limpo por duas capinas manuais, efetuadas aos 20 e aos 50 dias depois do plantio, período em que a cultura não apresentava desenvolvimento suficiente para suprimir o crescimento de plantas daninhas.

Para análise estatística, os dados populacionais de nematóides foram transformados em 
$\log (x+1)$, e as notas de fitointoxicação e perfilhos nas parcelas, em raiz quadrada de $x$. Os resultados foram submetidos à análise de variância e todas as médias foram comparadas pelo teste de Tukey a 5\% de significância.

\section{RESULTADOS E DISCUSSÃO}

Das espécies de nematóides economicamente importantes para a cana-de-açúcar, somente Pratylenchus zeae foi encontrada na área. Terbufós foi o nematicida mais eficiente, mantendo as populações significativamente inferiores às da testemunha, pelo menos até os cinco meses depois do plantio (Tabela 1). Aos sete meses (14.10.2002), o efeito residual dos produtos já havia terminado e as populações de $P$. zeae estavam semelhantes em todos os tratamentos (Tabela 1).

Os sintomas de fitointoxicação dos produtos foram primeiramente notados na amostragem efetuada aos 35 dias da aplicação dos herbicidas (DAA), acentuando-se aos 62 DAA e regredindo rapidamente após esse período (Tabela 2). Como descrito por Blanco et al. (1980), os sintomas caracterizaram-se pelo amarelecimento do limbo foliar, seguido pela requeima das folhas, começando pelo ápice e laterais das folhas e estendendo-se para a nervura central, ocorrendo, em alguns casos, secamento total das folhas da planta. As subparcelas com sintomas mais acentuados de fitointoxicação foram aquelas que receberam metribuzin + terbufós ou tebuthiuron + terbufós.

Tabela 1 - Populações de Pratylenchus zeae nas raízes (50 g) da variedade SP87-365 de cana-de-açúcar, aos 5, 7 e 9 meses de idade da cultura. Iracemápolis-SP, 2002/2003

\begin{tabular}{|l|c|c|c|}
\hline \multirow{2}{*}{ Tratamento } & \multicolumn{3}{|c|}{ Idade da cultura } \\
\cline { 2 - 4 } & $\begin{array}{c}5 \text { meses } \\
(6.8 .2002)\end{array}$ & $\begin{array}{c}7 \text { meses } \\
(14.10 .2002)\end{array}$ & $\begin{array}{c}9 \text { meses } \\
(6.12 .2002)\end{array}$ \\
\hline Testemunha & $7.960 \mathrm{a}$ & 4.580 & 3.320 \\
\hline Aldicarb & $1.410 \mathrm{ab}$ & 2.060 & 2.410 \\
\hline Carbofuran & $2.100 \mathrm{ab}$ & 1.400 & 1.500 \\
\hline Terbufós & $500 \mathrm{~b}$ & 1.390 & 1.660 \\
\hline Valor de F & $7,27^{* *}$ & $0,77^{\mathrm{ns}}$ & $0,95^{\text {ns }}$ \\
\hline CV $(\%)$ & 21,7 & 35,8 & 53,3 \\
\hline
\end{tabular}

Significância dos valores de $\mathrm{F}: * *=1 \%, *=5 \%,+=10 \%$ e ns $=$ nãosignificativo.
Considerando os dados médios para cada tratamento herbicida, os sintomas mais acentuados de fitointoxicação foram observados nas parcelas tratadas com metribuzin e tebuthiuron na amostragem efetuada aos 62 DDA e, para metribuzin, nas amostragens realizadas aos 35, 49 e 79 DAA. Em decorrência da fitointoxicação, parcelas tratadas com tebuthiuron apresentaram menor quantidade de perfilhos por metro do que a testemunha (Tabela 2).

Quanto aos nematicidas, na média, as maiores notas de fitointoxicação foram atribuídas às parcelas tratadas com terbufós (Tabela 2), revelando que o uso desse nematicida, concomitantemente ao de herbicidas, resulta em injúrias foliares mais severas do que quando se utiliza aldicarb ou carbofuran. Devido aos efeitos negativos da interação com herbicidas, parcelas tratadas com terbufós apresentaram número de perfilhos por metro semelhante ao das parcelas testemunhas, enquanto parcelas tratadas com aldicarb ou carbofuran apresentaram mais perfilhos que a testemunha. Esses dados sugerem que os efeitos benéficos do controle de nematóides na área (Tabela 1), resultante da aplicação de terbufós, foram anulados pelos efeitos prejudiciais das interações com alguns herbicidas.

Visto que os sintomas de fitointoxicação ocorrem quando os herbicidas atingem a cultura e considerando que no presente ensaio os produtos foram aplicados em pré-emergência, pode-se considerar que os herbicidas entraram nas plantas, provavelmente, via sistema radicular. O volume de chuvas após a aplicação (Tabela 3) foi suficiente para lixiviar os herbicidas até a região das raízes das plantas, e, nessa situação, eles foram absorvidos juntamente com os nematicidas. Como a detoxificação de produtos primários absorvidos, como herbicidas e nematicidas, é feita por várias enzimas, entre as quais a citocromo P450 monooxigenase (Hatzios \& Burgos, 2004; Reade et al., 2004), existente em quantidade limitada no interior da planta, a absorção de herbicida e nematicida provavelmente sobrecarregou o sistema metabólico das plantas, que passaram a manifestar sintomas de intoxicação, classicamente iniciados por clorose seguida por necrose foliar. 
Tabela 2 - Notas de fitointoxicação atribuídas à variedade SP87-365 de cana-de-açúcar em diversas datas de avaliação (dias após a aplicação do herbicida), de acordo com escala de EWRC (1964), e número de perfilhos por metro aos 5 meses de idade da cultura. Iracemápolis-SP, 2002/2003

\begin{tabular}{|c|c|c|c|c|c|c|c|c|}
\hline \multicolumn{2}{|c|}{ Tratamento } & \multicolumn{6}{|c|}{$\begin{array}{c}\text { Data de avaliação } \\
\text { (dias após a aplicação dos herbicidas) }\end{array}$} & \multirow{2}{*}{$\begin{array}{l}\text { Perfilhos por } \\
\text { metro }\end{array}$} \\
\hline Herbicida & Nematicida & $\begin{array}{l}5 / 4 \\
(21) \\
\end{array}$ & $\begin{array}{l}19 / 4 \\
(35) \\
\end{array}$ & $\begin{array}{c}3 / 5 \\
(49) \\
\end{array}$ & $\begin{array}{l}16 / 5 \\
(62) \\
\end{array}$ & $\begin{array}{c}3 / 6 \\
(79) \\
\end{array}$ & $\begin{array}{c}28 / 6 \\
(104)\end{array}$ & \\
\hline \multirow{4}{*}{ Testemunha } & Testemunha & 1,00 & 1,00 & 1,00 & 1,00 & 1,00 & 1,00 & 13,6 \\
\hline & Aldicarb & 1,25 & 1,00 & 1,00 & 1,25 & 1,00 & 1,00 & 15,3 \\
\hline & Carbofuran & 1,25 & 1,00 & 1,00 & 1,25 & 1,00 & 1,00 & 14,4 \\
\hline & Terbufós & 1,50 & 1,50 & 1,00 & 1,75 & 1,25 & 1,00 & 14,3 \\
\hline \multirow{4}{*}{ Clomazone } & Testemunha & 1,75 & $1,00 \mathrm{a}$ & 1,75 & 1,75 & 1,00 & 1,00 & $12,2 \mathrm{a}$ \\
\hline & Aldicarb & 1,00 & $1,00 \mathrm{a}$ & 1,50 & 1,75 & 1,25 & 1,00 & $13,1 \mathrm{ab}$ \\
\hline & Carbofuran & 1,25 & $1,25 \mathrm{ab}$ & 1,50 & 1,50 & 1,00 & 1,00 & $14,1 \mathrm{~b}$ \\
\hline & Terbufós & 1,25 & $1,75 \mathrm{~b}$ & 1,75 & 1,75 & 1,00 & 1,00 & $13,1 \mathrm{ab}$ \\
\hline \multirow{4}{*}{ Metribuzin } & Testemunha & 1,00 & $1,00 \mathrm{a}$ & $2,00 \mathrm{a}$ & 2,00 & $1,00 \mathrm{a}$ & 1,00 & 12,4 \\
\hline & Aldicarb & 1,25 & $1,00 \mathrm{a}$ & $2,25 \mathrm{a}$ & 2,25 & $1,25 \mathrm{ab}$ & 1,00 & 13,6 \\
\hline & Carbofuran & 1,00 & $1,25 \mathrm{ab}$ & $2,50 \mathrm{ab}$ & 2,50 & $1,75 \mathrm{~b}$ & 1,25 & 13,3 \\
\hline & Terbufós & 1,00 & $2,25 \mathrm{~b}$ & $3,00 \mathrm{~b}$ & 2,75 & $1,50 \mathrm{ab}$ & 1,25 & 13,0 \\
\hline \multirow{4}{*}{ Tebuthiuron } & Testemunha & 1,00 & 1,00 & $1,50 \mathrm{a}$ & 2,25 & $1,00 \mathrm{a}$ & 1,00 & $11,9 \mathrm{a}$ \\
\hline & Aldicarb & 1,50 & 1,25 & $1,50 a$ & 2,00 & $1,00 \mathrm{a}$ & 1,00 & $13,2 \mathrm{ab}$ \\
\hline & Carbofuran & 1,25 & 1,00 & $1,75 \mathrm{a}$ & 2,50 & $1,00 \mathrm{a}$ & 1,00 & $13,9 \mathrm{~b}$ \\
\hline & Terbufós & 1,25 & 1,00 & $3,00 \mathrm{~b}$ & 3,00 & $1,75 \mathrm{~b}$ & 1,00 & $11,8 \mathrm{a}$ \\
\hline \multirow{4}{*}{ Média (H) } & Testemunha & 1,19 & $1,13 a b$ & $1,00 \mathrm{a}$ & $1,31 \mathrm{a}$ & $1,06 \mathrm{a}$ & 1,00 & $14,4 \mathrm{~b}$ \\
\hline & Clomazone & 1,31 & $1,25 \mathrm{ab}$ & $1,63 \mathrm{~b}$ & $1,69 \mathrm{a}$ & $1,06 \mathrm{a}$ & 1,00 & $13,1 \mathrm{ab}$ \\
\hline & Metribuzin & 1,06 & $1,38 \mathrm{a}$ & $2,44 c$ & $2,38 \mathrm{~b}$ & $1,38 \mathrm{~b}$ & 1,13 & $13,1 \mathrm{ab}$ \\
\hline & Tebuthiuron & 1,25 & $1,06 \mathrm{~b}$ & $1,94 \mathrm{~b}$ & $2,43 \mathrm{~b}$ & $1,19 \mathrm{ab}$ & 1,00 & $12,7 \mathrm{a}$ \\
\hline \multirow{4}{*}{ Média (N) } & Testemunha & 1,19 & $1,00 \mathrm{a}$ & $1,56 a$ & $1,75 \mathrm{a}$ & $1,00 \mathrm{a}$ & 1,00 & $12,5 \mathrm{a}$ \\
\hline & Aldicarb & 1,25 & $1,06 \mathrm{a}$ & $1,56 \mathrm{a}$ & $1,81 \mathrm{ab}$ & $1,19 \mathrm{ab}$ & $\begin{array}{l}1,00 \\
1,00\end{array}$ & $13,8 \mathrm{~b}$ \\
\hline & Carbofuran & 1,19 & $1,12 \mathrm{a}$ & $1,69 \mathrm{a}$ & $1,94 \mathrm{ab}$ & $1,19 \mathrm{ab}$ & 1,06 & $13,9 \mathrm{~b}$ \\
\hline & Terbufós & 1,25 & $1,63 \mathrm{~b}$ & $2,19 \mathrm{~b}$ & $2,31 \mathrm{~b}$ & $1,38 \mathrm{~b}$ & 1,06 & $13,1 \mathrm{ab}$ \\
\hline \multirow{3}{*}{ Valores de F } & Herbicidas & $0,6684^{\text {ns }}$ & $2,2396^{\mathrm{ns}}$ & $10,8280 * *$ & $17,1723 * *$ & $2,8361^{+}$ & $1,0000^{\text {ns }}$ & $3,2372^{+}$ \\
\hline & Nematicidas & $0,0989^{\mathrm{ns}}$ & $13,5480 * *$ & $7,3286 * *$ & $3,4385^{*}$ & $3,0709 *$ & $1,0000^{\mathrm{ns}}$ & $4,4798 * *$ \\
\hline & $\mathrm{H} \times \mathrm{N}$ & $1,4176^{\text {ns }}$ & $3,1039 * *$ & $2,8138 *$ & $0,7052^{\mathrm{ns}}$ & $1,7374^{\mathrm{ns}}$ & $1,0000^{\mathrm{ns}}$ & $0,9573^{+}$ \\
\hline \multirow{2}{*}{ CV (\%) } & Herbicidas & 10,9 & 6,6 & 10,7 & 6,9 & 6,4 & 5,1 & 3,1 \\
\hline & Nematicidas & 15,0 & 11,5 & 11,4 & 13,8 & 13,7 & 5,9 & 4,4 \\
\hline
\end{tabular}

Significância dos valores de $\mathrm{F}: * *=1 \%, *=5 \%,+=10 \%$ e ns = não-significativo.

Tabela 3 - Precipitação pluviométrica $(\mathrm{mm})$ durante a fase inicial de condução do experimento. Iracemápolis-SP, 2002/2003

\begin{tabular}{|l|c|}
\hline \multicolumn{1}{|c|}{ Período } & $\begin{array}{c}\text { Chuva } \\
(\mathrm{mm})\end{array}$ \\
\hline 7 a 15/3 (do plantio à aplicação dos herbicidas) & 37 \\
\hline 16 a 31/3 & 116 \\
\hline Abril & 77 \\
\hline Maio & 74 \\
\hline Junho & 0 \\
\hline
\end{tabular}

Considerando os resultados obtidos por ocasião da colheita (Tabela 4), na média, parcelas tratadas com aldicarb ou carbofuran produziram até $12 \mathrm{t} \mathrm{ha}^{-1}$ a mais que a testemunha-incremento de produtividade geralmente encontrado em situações nas quais as populações de nematóides foram semelhantes às da área experimental (Dinardo-Miranda et al., 2001). O tratamento com terbufós, por sua vez, não diferiu da testemunha e também dos demais tratamentos (Tabela 4). Esses dados 
refletem exatamente aqueles observados no desenvolvimento inicial da cultura, expressos em número de perfilhos por metro (Tabela 2). Embora o terbufós tenha exercido bom controle de nematóides, não houve resposta significativa em termos de produtividade. A falta de resposta ao tratamento com terbufós não pode ser atribuída, entretanto, à interação com herbicidas, uma vez que mesmo nas parcelas sem herbicida (testemunhas) as subparcelas tratadas com terbufós apresentaram tendência de produzir menos que aquelas tratadas com carbofuran ou aldicarb. Outros fatores, portanto, devem estar relacionados à falta de resposta ao terbufós.

À semelhança do ocorrido nas parcelas sem herbicida (testemunha), naquelas tratadas com clomazone não houve diferença estatística entre os tratamentos nematicidas (Tabela 4). No entanto, quando o herbicida utilizado foi metribuzin ou tebuthiuron, o uso de aldicarb ou aldicarb e carbofuran, respectivamente, resultou em maiores produtividades do que a testemunha (Tabela 4). Por outro lado, nas parcelas tratadas com metribuzin + terbufós ou tebuthiuron + terbufós, que apresentaram os sintomas mais severos de injúrias foliares, no início do desenvolvimento da cultura (Tabela 2), foram obtidas produtividades semelhantes às das parcelas de metribuzin sem nematicida ou tebuthiuron sem nematicida. Esses dados revelam, portanto, que os sintomas de fitointoxicação observados no início do desenvolvimento da cultura não interferiram na produtividade agrícola (Tabela 4), mostrando que a cultura se recuperou dos danos iniciais, nas condições do presente ensaio.

Considerando os dados médios, não houve diferença entre os herbicidas e a testemunha quanto à produtividade agrícola, porém parcelas tratadas com clomazone produziram significativamente mais que as tratadas com metribuzin (Tabela 4).

Os dados do presente ensaio são concordantes com os de Negrisoli et al. (2004), que verificaram que os nematicidas não interferiram nas produtividades de parcelas tratadas com herbicidas, entre os quais metribuzin, colomazone e tebuthiuron. No entanto, são discordantes dos observados por DinardoMiranda et al. (2001b), os quais constataram que a aplicação de metribuzin em área tratada com carbofuran ou terbufós reduziu a produtividade da variedade RB845257. Também discordam dos dados de Dinardo-Miranda et al. (2001a), que observaram redução de produtividade da RB72454 tratada com tebuthiuron e terbufós.

Os resultados contraditórios, entretanto, sugerem que há muitos fatores, além da combinação nematicida e herbicida, que interferem na interação entre os produtos em cana-de-açúcar, dentre os quais se destacam variedades, tipo de solo e volume de chuvas após aplicação.

Tabela 4 - Produtividade de cana $\left(\mathrm{t} \mathrm{ha}^{-1}\right)$ no primeiro corte da variedade SP87-365, em função dos tratamentos. Iracemápolis-SP, 2002/2003

\begin{tabular}{|c|c|c|c|c|c|}
\hline \multirow{2}{*}{ Tratamento herbicida } & \multicolumn{5}{|c|}{ Tratamento nematicida } \\
\hline & Testemunha & Aldicarb & Carbofuran & Terbufós & Média \\
\hline Testemunha & 103,0 a $\mathrm{A}$ & 110,1 a A & 109,5 a $A$ & 103,6 a A & $106,6 \mathrm{AB}$ \\
\hline Clomazone & 105,4 a A & 114,6 a A & 115,7 a A & 107,8 a A & $110,9 \mathrm{~B}$ \\
\hline Metribuzin & 94,8 a A & $110,4 \mathrm{~b} \mathrm{~A}$ & $106,4 \mathrm{ab} A$ & $104,0 \mathrm{ab} \mathrm{A}$ & $103,9 \mathrm{~A}$ \\
\hline Tebuthiuron & 94,3 a $\mathrm{A}$ & $110,6 \mathrm{~b} \mathrm{~A}$ & $111,8 \mathrm{~b} \mathrm{~A}$ & $106,9 \mathrm{ab} \mathrm{A}$ & $105,9 \mathrm{AB}$ \\
\hline Média & $99,4 \mathrm{a}$ & $111,4 \mathrm{~b}$ & $110,9 \mathrm{~b}$ & $105,6 \mathrm{ab}$ & \\
\hline \multirow{4}{*}{ DMS - Tukey a 5\% } & \multicolumn{3}{|c|}{ Herbicidas } & \multicolumn{2}{|c|}{6,8} \\
\hline & \multicolumn{3}{|c|}{ Nematicidas } & \multicolumn{2}{|c|}{6,9} \\
\hline & \multicolumn{3}{|c|}{ Herbicidas dentro de nematicidas } & \multicolumn{2}{|c|}{13,6} \\
\hline & \multicolumn{3}{|c|}{ Nematicidas dentro de herbicidas } & \multicolumn{2}{|c|}{13,7} \\
\hline \multirow{2}{*}{$\mathrm{CV}(\%)$} & \multicolumn{3}{|c|}{ Herbicidas } & \multicolumn{2}{|c|}{5,8} \\
\hline & \multicolumn{3}{|c|}{ Nematicidas } & \multicolumn{2}{|c|}{6,7} \\
\hline
\end{tabular}

Médias na mesma linha seguidas por letras minúsculas iguais e médias na mesma coluna seguidas por letras maiúsculas iguais não diferem entre si pelo teste de Tukey a 5\% de significância. 
Uma vez que as variedades de cana-deaçúcar possuem diferentes sensibilidades a herbicidas, é certo que as mais sensiveis apresentem sintomas mais acentuados de fitointoxicação quando tratadas com nematicidas e herbicidas conjuntamente. Da mesma forma, a presença de outros interferentes no solo, como o teor de alumínio, também pode agravar os sintomas de fitointoxicação, visto que as plantas teriam que metabolizar, ao mesmo tempo, várias substâncias tóxicas: herbicida, nematicida e alumínio. Esse fato foi discutido por Cáceres (2005), que observou sintomas mais acentuados de fitointoxicação por herbicida em áreas tratadas com carbofuran, quando o solo apresentava alto teor de alumínio.

O volume de chuvas após a aplicação dos herbicidas também pode interferir na interação, pois, segundo Christoffoleti \& López-Ovejero (2005), herbicidas de alta solubilidade, como tebuthiuron $(2.500 \mathrm{ppm}$ a $\left.25{ }^{\circ} \mathrm{C}\right)$, metribuzin e clomazone (1.100 ppm), quando utilizados em períodos de alta precipitação pluviométrica, podem ser lixiviados, o que aumenta o potencial de fitotoxicidade para a cultura, por reduzir a seletividade por posicionamento no solo, principalmente em solos arenosos. Assim, tem-se a importância da chuva após a aplicação dos herbicidas para o aparecimento de sintomas de fitointoxicação. Como no presente ensaio a precipitação pluviométrica nos primeiros 15 dias após a aplicação dos herbicidas atingiu o índice de $116 \mathrm{~mm}$, o agravamento das injúrias foliares indica que esse volume de chuvas foi suficiente, nesse tipo de solo, para lixiviar os herbicidas até a região do sistema radicular das plantas, situação em que foram absorvidos juntamente com os nematicidas.

Os dados observados no presente experimento permitiram concluir que a aplicação na mesma área de metribuzin + terbufós ou tebuthiuron + terbufós resultou em injúrias foliares na cana-de-açúcar, no início do desenvolvimento da cultura, sem contudo interferir na produtividade agrícola, mostrando que a cultura se recuperou dos danos iniciais, nas condições do presente ensaio. Não se observou redução significativa de produtividade em função da aplicação conjunta de nematicidas e herbicidas. Na média, aldicarb e carbofuran incrementaram a produtividade de colmos em $12 \mathrm{t} \mathrm{ha}^{-1}$. Parcelas tratadas com clomazone produziram, em média, significativamente mais que as tratadas com metribuzin.

\section{LITERATURA CITADA}

BLANCO, H. G. et al. Fitotoxicidade em cana-de-açúcar causada pela interação de inseticida e herbicida residual. O Biológico, v. 46, n. 10, p. 235-240, 1980.

CÁCERES, N. T. A relação entre herbicidas e nematicidas em cana-de-açúcar: uma nova abordagem. STAB - Açúcar, Álcool e Subprod., v. 23, n. 5, p. 48-52, 2005.

CHRISTOFFOLETI, P. J.; LÓPES-OVEJERO, R. F. Dinâmica dos herbicidas aplicados ao solo na cultura da cana-de-açúcar. Piracicaba: BASF, 2005. 49 p.

COOLEN, W. A.; D'HERDE, C. J. A method for the quantitative extraction of nematodes from plant tissue. Ghent: State Nematology and Entomology Research Station, 1972. $77 \mathrm{p}$.

COPERSUCAR. Nematóides parasitos da cana-de-açúcar e seu controle. In: SEMINÁRIO DE TECNOLOGIA AGRONÔMICA, 1., Piracicaba. Anais... Piracicaba:1982. p. $133-153$.

DINARDO-MIRANDA, L. L. et al. Efeitos da interação entre nematicidas e herbicidas aplicados em cana de ano. STAB Açúcar, Álcool e Subprod., v. 20, n. 2, p. 32-36, 2001a.

DINARDO-MIRANDA, L. L. et al. Efeitos da interação entre nematicidas e herbicidas em cana-de-açúcar. Nematologia Bras., v. 25, n. 2, p. 197-204, 2001 b.

DINARDO-MIRANDA, L. L. et al. Reação de variedades de cana-de-açúcar a Pratylenchus zeae. STABB - Açúcar, Álcool e Subprod., v. 17, n. 2, p. 39-41, 1998.

DINARDO-MIRANDA, L. L. et al. Danos causados por nematóides a variedades de cana-de-açúcar em cana planta. Nematol. Bras., v. 27, n. 1, p. 69-74, 2003.

EUROPEAN WEED RESEARCH COUNCIL. Report of $3^{\text {rd }}$ and $4^{\text {th }}$ meetings of EWRC. Citiee of methods in weed research. Weed Res., v. 4, p. 88, 1964.

HATZIOS, K. K.; BURGOS, N. Metabolism-based herbicide resistance: regulation by saferers. Weed Sci., v. 52, n. 3, p. 454-467, 2004.

JENKINS, W. R. A rapid centrifugal-flotation technique for separating nematodes from soil. Plant Disease Rep., v. 48, n. 9, p. $696,1964$.

NEGRISOLI, E. et al. Seletividade de herbicidas aplicados em pré-emergência na cultura da cana-de-açúcar tratada com nematicidas. Planta Daninha, v. 22, n. 4, p. 567-575, 2004.

PITELLI, R. A. Interferência de plantas daninhas em culturas agrícolas. Inf. Agropec., v. 11, n. 23, p. 16-27, 1985.

READE, J. P. H. et al. A role of glutothione S-transferases in resistance to herbicides in grasses. Weed Sci., v. 52, n. 3, p. 468-476, 2004. 